\title{
Premature Division of the Inferior Laryngeal Nerve in Surgery and in ENT and Cervico-Facial Surgery in Mali
}

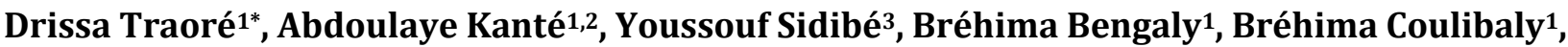 \\ Babou Ba ${ }^{2}$, Drissa Ouattara', Siaka Diallo', Mariam Daou' ${ }^{4}$, Birama Togola1, Nouhoum Ongoïba1,2
}

${ }^{1}$ Service of Surgery B. CHU Point G, Bamako, Mali

${ }^{2}$ Laboratory of Anatomy of the Faculty of Medicine and Odontostomatology, Bamako, Mali

${ }^{3}$ ENT and Head and Neck Surgery Department, CHU “Mother-Child”, Bamako, Mali

${ }^{4}$ Service of Neurology, CHU Gabriel Touré, Bamako, Mali

Email: *traored2003@yahoo.fr

How to cite this paper: Traoré, D., Kanté, A., Sidibé, Y., Bengaly, B., Coulibaly, B., Ba, B., Ouattara, D., Diallo, S., Daou, M., Togola, B. and Ongoïba, N. (2019) Premature Division of the Inferior Laryngeal Nerve in Surgery and in ENT and Cervico-Facial Surgery in Mali. Forensic Medicine and Anatomy Research, 7, 1-7.

https://doi.org/10.4236/fmar.2019.71001

Received: October 3, 2018

Accepted: December 5, 2018

Published: January 2, 2019

Copyright () 2019 by authors and Scientific Research Publishing Inc. This work is licensed under the Creative Commons Attribution International License (CC BY 4.0).

http://creativecommons.org/licenses/by/4.0/ (c) (i) Open Access

\begin{abstract}
The purpose of this study was to study the frequency of premature division of the inferior laryngeal nerve and its consequences in thyroid surgery. Methodology: We realized a forward-looking and retrospective study from January, 1979 till December, 2017 in the service of surgery B to the University hospital of the Point G of Bamako and in the service of ENT and cervico-facial surgery of the CHU "mother-child", the Luxembourg of Bamako (Mali). All the patients operated in both services for mild goiters were included. Cancers and other thyroid pathologies were not included. The diagnosis of mild goiter was paused by the histological examination realized on all the surgical specimens. Results: On 2109 dissections of the lower laryngeal nerve realized during the surgical operations on the thyroid $95.1 \%$ of the cases, the nerve had a single branch; in $4.1 \%$ of the cases, the nerve had two branches; and in $0.8 \%$ of the cases, the nerve had more than 2 branches. Conclusion: The complications of the thyroid surgery in touch with the hurts of the lower laryngeal nerve are known. However, our study shows that these do not seem to be influenced by the premature division of the lower laryngeal nerve.
\end{abstract}

\section{Keywords}

Anatomy, Inferior Laryngeal Nerve, Recurring Nerve, Thyroid Surgery, Goiter

\section{Introduction}

The inferior laryngeal nerve (ILN) assures the driving innervation of the intrin- 
sic muscles of the larynx except the cricothyroid muscle. It starts with the pneumogastric nerve and then ties right to the subclavian artery and left to the aorta butt. In its route, to the left, it rises in the posterior mediastinum, in the dihedral tracheo-œsophageal, then in the thyroid changing room and is going to penetrate to the lower edge of the cricoid cartilage to end in the larynx. To the right, it rises between the common carotid and the vertebral artery, and then it goes to the thyroid changing room to penetrate into the larynx [1].

- Before its penetration in the larynx, variations can be observed. These variations concern not only its route but also its division: for Lahey [2], the high division of the nerve is above the lower thyroid arteriovenous crossing; the low division is below the lower thyroid arteriovenous crossing;

o for Morrisson [3], there are three levels of division: thyroid upper over horizontal passing in the middle of the cricoid cartilage; thyroid lower passing below the tangent in both lower poles of the thyroid lobes; thyroid average situated between both lines above;

- Virno [4] and Bellemain [5] used the lower horn of the thyroid cartilage as mark.

Modifications of the route can be observed at the subject presenting a goiter. When the goiter is voluminous, the inferior laryngeal nerve can be repulsed either laterally, or ventrally, or dorsally. The plunging goiters can modify the intra-thoracic route of the lower laryngeal nerve. These pathologies have no consequence on the number of branches of the inferior laryngeal nerve, but can modify reports between this nerve and the other structures, without modifying generally the topography of the division of the nerve with regard to the thyroid.

In the thyroid surgery, complications in touch with the hurts of the inferior laryngeal nerve were observed by Dupuytren, Wolfler, Jankowski, Berad, Crile and Berlin [6]. These hurts can be influenced by the variations of the inferior laryngeal nerve.

In Africa, very few anatomical works were realized on the premature division of the inferior laryngeal nerve. To mitigate this deficit of research on the premature division to the subject melanoderm, we introduced this study which had for objectives to determine the frequency of the premature division of the ILN and to determine the consequence of this premature division on the risk of lesion per operating of the ILN.

\section{Materials and Methods}

We realized a retrospective study from January, 1979 till December, 2011 and prospective from January, 2012 till December, 2017 (that is 38 years of study) in the service of surgery B to the University hospital Point G of Bamako and in the service of ENT and cervico-facial surgery of the CHU "mother-child, the Luxembourg of Bamako (Mali).

All the patients operated in both services for mild goiters were included. Cancers and other thyroid pathologies were not included. 
The diagnosis of mild goiter was made by the histological examination realized on all the surgical specimens.

The group of hyperthyroid patients was handled medically with antithyroid ones of synthesis to have aneuthyroïdy before being scheduled for the surgical operation.

A complete clinical examination, a dosage of free T4, ultrasensitive TSH, a preoperative biological balance sheet and a cervical ultrasound were made at all the patients. The patients all had a consultation systematic ENT meadow and operating comment to study the mobility of vocal cords.

For the operation, the sick person is installed in spine position; the head is in extension rest on a masthead in frost of silicon. A block placed under his shoulders facilitates this extension. The latter are lowered at the most to clear well the neck. The way at first was a previous transverse cervicotomy type Kocher (Figure 1).

After section of the cutaneous trunci of the neck, the previous jugular veins are ligatured and split. An unsticking is made between the venous plan ventrally, the sterno-cleido-mastoid muscles dorsally and laterally, and the sterno-thyroid muscles dorsally and medially. The unsticking achieves cranially the lower edge of the thyroid cartilage and caudally the upper edge of the manubrium sternal. A median vertical section is then realized up to the thyroid capsule. No muscle is split in this way at first. The thyroid capsule is opened.

The inferior laryngeal nerve is spotted in a triangle lined by the primitive carotid outside, the tracheainside and the thyroid at the top. It is white sinuous, browsed by a very visible arteriol. The dissection of the deep face of the lobe is led from the outside inside, until the penetration of the nerve in the larynx, to the lower edge of the cricoid cartilage. To the left, the nerve walks in the dihedral tracheo-œsophageal. To the right it is in more side position. We defined the premature division as being any division of the nerve below the tangent right in the lower edge of the thyroid lobes.

We defined by lesion of the inferior laryngeal nerve, any paralysis or paresis of a vocal cord appeared in operating comment which persisted after month.

The data were seized and analyzed on the software Ear information (version 6 ). The test of $X^{2}$ and Student were used to compare our results with those of the literature. The threshold of meaning was fixed to 0.05 .

\section{Results}

\subsection{Sociodemographic Data}

The average age of the patients was of 37 years with extremes of 10 years and 78 years, the age bracket 40 - 49 years represented $22.8 \%$. It was about 136 men and 919 women (Figure 2 and Table 1), 282 (26.7\%) lived in Bamako whereas 773 $(73.3 \%)$ came from 11 regions of Mali and $756(71.7 \%)$ had a low socioeconomic level. 


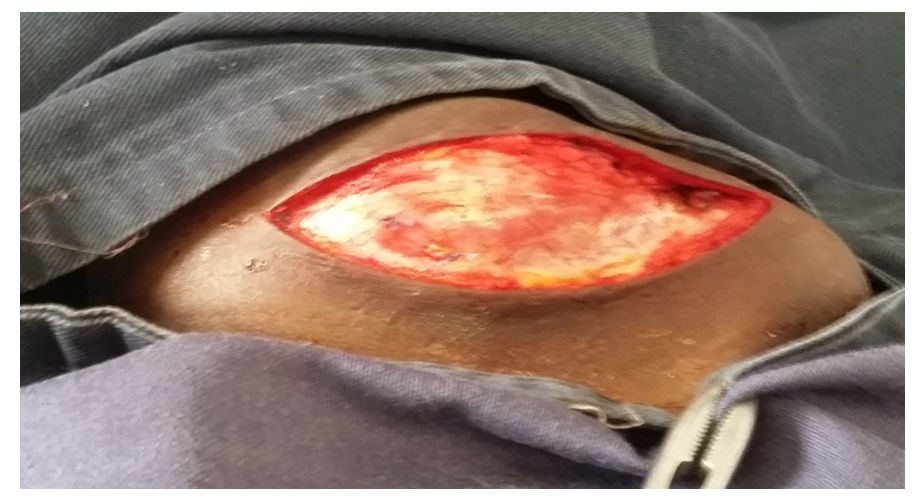

Figure 1. Showing the previous typical cervical section Kocher.

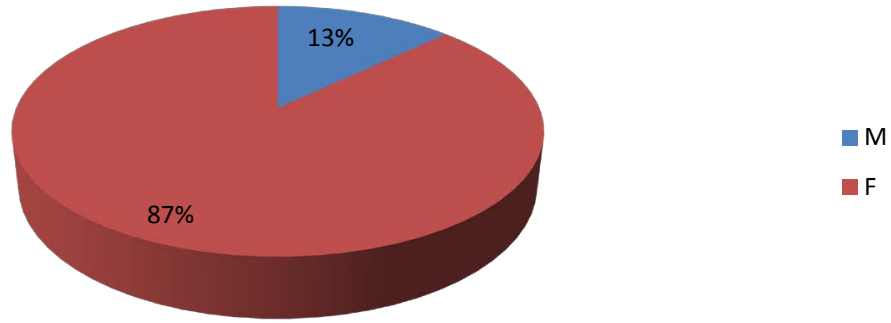

Figure 2. Distribution of the patients according to the sex.

Table 1. Distribution of the patients according to the age bracket.

\begin{tabular}{ccc}
\hline Age bracket (years) & Number & Percentage (\%) \\
\hline $10-19$ & 36 & $3.4 \%$ \\
$20-29$ & 100 & $9.5 \%$ \\
$30-39$ & 173 & $16.4 \%$ \\
$40-49$ & 355 & $33.6 \%$ \\
$50-59$ & 291 & $27.6 \%$ \\
$60-69$ & 73 & $6.9 \%$ \\
70 et plus & 27 & $2.6 \%$ \\
Total & 1055 & $100 \%$ \\
\hline
\end{tabular}

\subsection{Anatomo-Pathological Data}

The histological examination was made at all the sick. We found a goiter colloid in 77\%. The reserved etiologies are represented in Table 2.

\subsection{Global Frequency of the Premature Division of the Lower Laryngeal Nerve}

On 2109 dissected inferior laryngeal nerves, we had 2006 cases (95.1\%) of troncular nerves, 87 cases (4.1\%) of double inferior laryngeal nerves, 11 cases $(0.5 \%)$ of triple laryngeal nerves, 5 cases $(0.3 \%)$ of inferior laryngeal nerve quadruple. A premature division of the inferior laryngeal nerve was found in $4.8 \%$ (101 cases). 
Table 2. Etiologies of goiters.

\begin{tabular}{ccc}
\hline Etiologies of goiters & Number & Percentage \\
\hline Toxic multi-hetero- nodular goiter & 272 & $25.8 \%$ \\
Grave's disease & 151 & $14.3 \%$ \\
Basedowifie goiter & 61 & $5.8 \%$ \\
Hyperthyroid unique nodule & 35 & $3.3 \%$ \\
Hypofunctional goiter & 536 & $50.8 \%$ \\
Total & 1055 & $100 \%$ \\
\hline
\end{tabular}

\subsection{Frequency of the Premature Division of the Lower Laryngeal Nerve according to the Highly-Rated}

We dissected 1072 right inferior laryngeal nerves and 1037 left. The division of the inferior laryngeal nerves according to the number of branches and according to the side is presented in Table 3. In $95.3 \%$ of the cases, the nerve is troncular to the left against $94.9 \%$ to the right. There is no statistically significant difference for the left-hand side and the right-hand side $(\mathrm{p}=0.8)$.

\subsection{Frequency of the Premature Division of the Inferior Laryngeal Nerve according to the Sex}

We dissected 272 inferior laryngeal nerves to male subjects and on 1837 to the female subjects. The division of the inferior laryngeal nerves according to the number of branches and according to the sex is presented in Table 4. In 95.6\% of the cases, the nerve is troncular to the male subjects, against $95 \%$ to the female subjects. There is no statistically significant difference for the number of branches according to the sex $(\mathrm{p}=0.9)$.

There is no statistically significant difference for the number of branches according to the sex $(\mathrm{p}=0.9)$.

\subsection{Frequency of the Lesion of the Inferior Laryngeal Nerve in Case of Its Premature Division}

Table 5 shows that in the cases where the inferior laryngeal (ILN) nerve is troncular (2006 cases), the accidental lesion of this nerve arose in 27 cases, is a frequency of lesion of the ILN in $1.34 \%$ of the cases. But in the cases where the ILN is multiple ( 103 cases), the accidental lesion of this nerve arose in 2 cases that is a frequency of lesion of the ILN in $1.94 \%$ of the cases. The difference is not statistically significant $(p=0.07)$. Thus the number of branches of division of the ILN does not influence the arisen of a lesion of this nerve per operating.

\section{Discussion}

In our study, the global frequency of the premature division of the inferior laryngeal nerve was $4.8 \%$. This rate is statistically little different from that reported by Ongoïba ( $\mathrm{n}=1133 ; 4.6 \%)$. But Morrisson reported a premature division in 
Table 3. Distribution of the inferior laryngeal nerves according to the number of branches and the side.

\begin{tabular}{ccccccc}
\hline \multirow{2}{*}{$\begin{array}{c}\text { Sides } \\
\text { Number of } \\
\text { branches }\end{array}$} & Number & $\%$ & Number & $\%$ & Number & $\%$ \\
\cline { 2 - 6 } One & 1017 & 94.9 & 989 & 95.4 & 2006 & 95.1 \\
\hline Two branches & 46 & 4.3 & 41 & 3.9 & 87 & 4.1 \\
Three & 6 & 0.5 & 5 & 0.5 & 11 & 0.5 \\
Four & 3 & 0.3 & 2 & 0.2 & 5 & 0.3 \\
Total & 1072 & $100 \%$ & 1037 & $100 \%$ & 2109 & $100 \%$ \\
\hline
\end{tabular}

Table 4. Distribution of the lower laryngeal nerves according to the number of branches and the sex.

\begin{tabular}{ccccccc}
\hline \multirow{2}{*}{$\begin{array}{c}\text { Sex } \\
\text { Number of } \\
\text { branches }\end{array}$} & \multicolumn{2}{c}{ Male } & \multicolumn{2}{c}{ Feminine } & \multicolumn{2}{c}{ Total } \\
\cline { 2 - 7 } & Number & $\%$ & Number & $\%$ & Number & $\%$ \\
\hline one & 260 & 95.6 & 1746 & 95 & 2006 & 95.1 \\
two branches & 9 & 3.3 & 78 & 4.3 & 87 & 4.1 \\
upper for two & 3 & 1.1 & 13 & 0.7 & 16 & 0.8 \\
Total & 272 & 100 & 1837 & 100 & 2109 & 100 \\
\hline
\end{tabular}

Table 5. Frequency of lesion of the lower laryngeal nerve according to the number of its branches.

\begin{tabular}{|c|c|c|c|c|c|}
\hline \multirow{2}{*}{$\begin{array}{l}\text { Lesion of ILN Number } \\
\text { of branches of the ILN }\end{array}$} & \multicolumn{2}{|c|}{ Not } & \multicolumn{2}{|c|}{ Yes } & \multirow{2}{*}{ Total } \\
\hline & Number & $\%$ & Number & $\%$ & \\
\hline Unique & 1979 & 98.66 & 27 & 1.34 & 2006 \\
\hline Multiple & 101 & 98.06 & 2 & 1.94 & 103 \\
\hline Total & 2080 & 98.62 & 29 & 1.38 & 2109 \\
\hline
\end{tabular}

$21 \%$ of the cases (according to him, the division being considered premature, if it arises below the tangent in the lower poles of the thyroid); while for N' Guyen [7] the nerve divides before reaching the larynx in $3.3 \%$ of the cases, and Chayriguet [8] reported $1 \%$ of premature division.

To the right this premature division was $4.1 \%$ against $4.9 \%$ to the left in our study, while in the study of Ongoïba a premature division was found in $4.1 \%$ to the right against $4.9 \%$ to the left.

Our results are statistically few of those of N'Guyen and Ongoïba. The differences between our results and those of the other authors are significant $(\mathrm{p}=$ 0.001). These differences could give some explanation by the definitional differences of anatomical marks taken to define the premature division of the inferior laryngeal nerve.

In 2006 cases of inferior laryngeal nerve troncular we had 27 accidental hurts of the inferior laryngeal nerve (1.34\%), but in 103 cases of premature division of 
the inferior laryngeal nerve, we had 2 accidental hurts of the inferior laryngeal nerve (that is 1.94\%). Soulet [9] reported 6 hurts of the inferior laryngeal nerve on 319 cases of halving of the nerve (that is $0.4 \%$ ). Ongoïba found 1 accidental lesion on 53 cases of premature division of the inferior laryngeal nerve (that is $1.9 \%)$. The difference between the results reported by Soulet and Ongoïba and ours is not statistically significant $(\mathrm{p}>0.05)$. Consequently the premature division of the inferior laryngeal nerve does not seem to influence the risk of its lesion per operating.

\section{Conclusion}

The location of the inferior laryngeal nerve is an essential time during the thyroid surgery. It allows to decrease the complications in touch with the hurts of the inferior laryngeal nerve. According to our study, these do not seem to be influenced by the premature division of the inferior laryngeal nerve.

\section{Conflicts of Interest}

We, authors of this article, declare that there is no conflict of interests.

\section{References}

[1] Ongoïba, N., Sidibé, Y.N., Berété, S., Sissoko, F., Traore, A.K. and Koumaré, A.K. (2002) Inferior Laryngeal Nerve: Premature Division. Medical Mali, 3-4, 58-60.

[2] Lahey, F.H. (1944) Exposure of the Recurrent Laryngeal Nerve in Thyroid Operations. Further Experience. Surgery Gynecology Obstetric, 78, 239-244.

[3] Morrisson, L.F. (1952) Recurrent Laryngeal Nerve Paralysis. A Revised Conception Based on the Dissection of Hundred Cadavers. Annals of Otolaryngology, 61, 567-592.

[4] Virno, F. (1959) Synthetic Review and Anatomical Observation on the Elapsed One, on the Variation and on the Relationships of the Inferior Laryngeal Nerve (Recurrent) in the Space Retro Cricoid. Anatomy and Surgery, 1-2, 35-55.

[5] Bellemain, J. (1971) The Recurring Nerve in the Thyroid Changing Room. Anatomical Study about 50 Cases. Thesis Medicine, Lyon, 181.

[6] Berlin, D.D. (1935) The Recurrent Laryngeal Nerves in Total Ablation of the Normal Thyroid Gland. Surgery Gynecology Obstetric, 60, 19-26.

[7] N'Guyen, Mr. (1987) Branches Air Terminals of the Inferior Laryngeal Nerve. Study about 60 Dissections. Thesis Medicine, Grenoble.

[8] Chayriguet, I. (1993) The Not Recurring Nerve. Danger in Thyroid Surgery Parathyroid (about 6 Cases). Thesis Medicine, Strasbourg, 89.

[9] Soulet, J. (2000) The Complications Recurrentials of the Surgery of the Thyroid Gland. Thesis Medicine, Poitiers, 97. 